\title{
ZS Research Square

\section{Pleiotropic Effects of Pure Statin May Provide More Cardiac Benefits than Ezetimibe-Statin in a Comparable Intensity for Type 2 Diabetes Mellitus Patients with Extremely Atherosclerotic Cardiovascular Disease Risks}

\section{Yu-Cheng Kao}

CGMH: Chang Gung Memorial Hospital

Tien-Hsing Chen

Chang Gung Memorial Hospital

Chi-Hung Liu

Chang Gung Memorial Hospital

Jawl-Shan Hwang

Chang Gung Memorial Hospital

Ching-Chung Hsiao

Chang Gung Memorial Hospital

Yu-Sheng Lin

Chang Gung Memorial Hospital

Chun-Tai Mao

Chang Gung Memorial Hospital

Ming-Jui Hung

Chang Gung Memorial Hospital

Yan-Rong Li ( $\sim$ mr8252@cgmh.org.tw)

Chang Gung Memorial Hospital Linkou Main Branch: Chang Gung Memorial Hospital

\section{Research}

Keywords: Statin, Ezetimibe, Pleiotropic effect, Type 2 diabetes mellitus, Cardiovascular outcome

Posted Date: September 15th, 2020

DOI: https://doi.org/10.21203/rs.3.rs-74077/v1

License: (c) (i) This work is licensed under a Creative Commons Attribution 4.0 International License.

Read Full License 


\section{Abstract}

Background: Atorvastatin 40mg (ATOR 40) and ezetimibe 10mg/simvastatin 20mg (EZ-SIM 20) have comparable reductions of low-density lipoprotein cholesterol (LDL-C) but cardiovascular (CV) outcomes between these two therapies are unclear. Our real-world cohort study is to test the hypothesis of pleiotropic effects of purely higher dose statin on CV outcomes beyond comparable reductions of LDL-C, especially for extremely CV risk patients.

Methods: Between January 1, 2007 and December 31, 2013, a total of 3372 patients with type 2 diabetes mellitus (T2DM) admitted due to acute coronary syndrome (ACS) or acute ischemic stroke (AIS) were selected as the study cohort from the Taiwan National Health Insurance Research Database. Clinical outcomes were evaluated by ATOR 40 group $(n=1686)$ matched with EZ-SIM 20 group $(n=1686)$. Primary composite outcome includes CV death, non-fatal myocardial infarction, and non-fatal stroke. Secondary composite outcome includes hospitalization for unstable angina (HUA), percutaneous coronary intervention $(\mathrm{PCl})$, and coronary artery bypass grafting (CABG).

Results: With a mean follow-up of 2.4 years, no significant difference of primary composite outcome was observed between ATOR 40 and EZ-SIM 20 groups (subdistribution hazard ratio [SHR], 1.09; 95\% confidence interval [CI], 0.95-1.25). Nevertheless, ATOR 40 group had lower risks of HUA (SHR, 0.50; 95\% $\mathrm{Cl}, 0.35-0.72), \mathrm{PCl}(\mathrm{SHR}, 0.82 ; 95 \% \mathrm{Cl}, 0.69-0.97)$ and CABG (SHR, $0.62 ; 95 \% \mathrm{Cl}, 0.40-0.97)$ than EZ-SIM 20 group.

Conclusions: For T2DM patients after ACS or AIS, ATOR 40 may have lower risks of HUA, PCI and CABG than EZ-SIM 20.

\section{Introduction}

Type 2 diabetes mellitus (T2DM) is considered as a cardiovascular (CV) disease equivalent and is at risks of $\mathrm{CV}$ events and mortality which are two to four times than those in the general population $[1,2]$. In patients with T2DM, those with myocardial infarction or ischemic stroke are vulnerable for the further CV events $[3,4]$ and even classified as extremely atherosclerotic cardiovascular disease (ASCVD) risk patients by a recent definition [5]. For these patients, high-intensity statins should be administered to achieve low-density lipoprotein cholesterol $(L D L-C) \geq 50 \%$ reduction or to meet the individual goal of LDL$\mathrm{C}$ according to the different guidelines [5-8]. For either primary or secondary prevention of CV diseases, the concept of "the lower, the better" is verified from the results of numerous trials 3-hydroxy-3methylglutaryl coenzyme A (HMG-CoA) reductase inhibitors (statins) and landmark studies of non-statin LDL-C lowering agents, such as ezetimibe $[9,10]$ or proprotein convertase subtilsin-kexin type 9 (PCSK9) inhibitors $[11,12]$. However, one clinical question could be interesting and that is "Is there a different CV outcome between pure statin and ezetimibe-statin therapies when having a comparable reduction of LDLC or goal ?" 
Atorvastatin $40 \mathrm{mg}$ (ATOR 40) and ezetimibe $10 \mathrm{mg} /$ simvastatin $20 \mathrm{mg}$ (EZ-SIM 20) theoretically have a similar and comparable LDL-C lowering effect $[13,14]$ and could be categorized as a high-intensity LDL-C lowering agent $[15,16]$. Nevertheless, ATOR 40 may significantly have more reduction of high sensitivity C-reactive protein (hs-CRP) compared to EZ-SIM 20 (reduction of hs-CRP: 28.6\% versus 21.4\%) [14]. Besides, the pleiotropic effects of statins, such as decreasing oxidative stress, improving endothelial dysfunction, lowering endothelial cell apoptosis, alleviating inflammation and beneficial to the immune system which are independent of LDL-C reduction and regardless of the level of LDL-C have been supported by the literatures [17-19]. Some researches which were conducted with randomizing healthy volunteers or patients with coronary artery disease by comparing higher dose statins with a combination of lower dose statins and ezetimibe revealed more improvements in endothelial function and vascular inflammation by the higher dose statins in a comparable reduction of LDL-C [20-23] but some other studies did not observe the same findings [24-26]. Therefore, even in a comparable reduction of LDL-C, whether purely higher dose statins are better than a combination of ezetimibe and lower dose statins is still inconclusive. Moreover, these studies are not designed specifically to examine the major and solid CV outcomes, such as CV death, non-fatal myocardial infarction (MI), non-fatal stroke, hospitalization for unstable angina ( $\mathrm{HUA}$ ), percutaneous coronary intervention (PCI), and coronary artery bypass grafting (CABG). Therefore, although there is a similar and comparable LDL-C lowering effect from ATOR 40 and EZ-SIM 20, the CV outcomes between the purely higher dose statin and ezetimibe-statin therapies are still unclear, especially for extremely CV risk patients who tend to be more vulnerable to suffer from further major CV diseases within a relatively short period and could significantly get more CV benefits with adequate treatments because the effects of statins are better in secondary prevention than those in primary prevention. Given the uncertain CV effects between ATOR 40 and EZ-SIM 20 on patients with extremely CV risks, we used data from Taiwan's National Health Insurance Research Database (NHIRD) to conduct a nationwide and population-based cohort study to test the hypothesis of pleiotropic effects of the purely higher dose statins playing a role in CV outcomes beyond comparable reductions of LDL-C by analyzing T2DM patients after acute coronary syndrome (ACS) or acute ischemic stroke (AIS) who were treated ATOR 40 and EZ-SIM 20, respectively.

\section{Materials And Methods}

\subsection{Data source}

The National Health Insurance (NHI) program in Taiwan is since 1995 and covers the medical needs of $99.8 \%$ of 23 million people in the country. All standardized information and data of in this healthcare services are prospectively recorded by the NHIRD and contains inpatient and outpatient data, including date of birth, sex, diagnosis codes (International Classification of Diseases, Ninth Revision, Clinical Modification [ICD-9-CM] codes), drug prescriptions, surgical procedures, admission dates, hospitalizations, discharge dates, and expenditure which has been validated by the previous researches [27-31]. The ethics approval and protocol of this study were approved by the Ethics Institutional Review Board of Linkou Chang Gung Memorial Hospital. 


\subsection{Identification of study cohort}

The current study was a nationwide population-based, observational and open cohort using retrospectivecollected data from the NHIRD between January 1, 2007 and December 31, 2013. We identified patients with diagnoses of T2DM (excluding type 1 diabetes mellitus) between January 1, 2007 and December 31, 2013. Only 121,760 T2DM patients admitted with a principal diagnosis of ACS or AIS were included for analysis. After relevant exclusion, 6,959 patients with T2DM aged $\geq 40$ years who were admitted due to ACS or AIS were eligible for analyses and after propensity score matching (PSM) in a 1:1 ratio, a total of 3,372 subjects ( 1,686 subjects in the ATOR 40 group and 1,686 subjects in the EZ-SIM 20 group) were included into the final analysis (Figure 1). The definition of the index date was the date of discharge. The follow-up period was based on the index date to the date of death or December 31, 2013.

\subsection{Exposure of study statin}

During the study period, patients received these two kinds of statin-containing drugs according to the lipid-lowering guidelines in Taiwan. T2DM patients with elevated level of LDL-C $\geq 130 \mathrm{mg} / \mathrm{dL}$ received $\mathrm{NHI}$-paid LDL-C lowering agents to reach the therapeutic goal of LDL-C. The treatment goal of T2DM patients with established CV diseases by NHI in Taiwan was less than $100 \mathrm{mg} / \mathrm{dL}$ during the study period. Eligible patients who received study drugs within 30 days of the index date were divided into two groups according to the prescribed LDL-C lowering agents, the ATOR 40 group and the EZ-SIM 20 group, respectively. This definition of exposure of study drugs was reported in our previous publications [32-34].

\subsection{Ascertainment of T2DM, ACS and AIS}

The diagnosis of T2DM is validated according to ICD-9-CM codes where at least four visits of outpatient corresponded to an accuracy of $95.7 \%$ and with prescriptions of oral anti-diabetic agents corresponded to an accuracy of $99 \%$ [35]. We identified patients with T2DM based on diagnosis code and anti-diabetic agents simultaneously. The inclusions of ACS and AIS were requiring a principal diagnosis of admission. The diagnosis codes of ACS and AIS have been validated in previous NHIRD studies that have obtained high positive predictive values with $\geq 95 \%[27,29,30]$.

\subsection{Covariates measurements}

Comorbidities and histories of event at baseline were identified based on ICD-9-CM diagnosis codes (Supplemental Table 1). Comorbidities were defined as at least two outpatient visits or anyone inpatient diagnosis in the previous year of the index date. Histories of event was detected using anyone inpatient diagnosis before the index date which can be tracked to year 1997. The baseline medication was defined as the medications prescribed in the outpatient visits or the refill in the pharmacy within 30 days of the index date.

\subsection{Ascertainment of primary, secondary and safety outcomes}


The primary composite outcome was an endpoint of CV death, non-fatal Ml, and non-fatal stroke. The occurrences of ACS and AIS were defined as a principal inpatient diagnosis. The definition of CV death is the criteria of the Standardized Definitions for Cardiovascular and Stroke Endpoint Events in ClinicalTrials by the FDA in the United States.

The secondary composite CV outcome was defined as hospitalization for unstable angina (HUA), percutaneous coronary intervention ( $\mathrm{PCl}$ ), and coronary artery bypass grafting (CABG). The occurrence of HUA was defined as a principal inpatient diagnosis. Information of PCl and CABG was extracted using the Taiwan NHI reimbursement codes of inpatient claims. Other secondary outcomes included hospitalization for heart failure (HHF), and all-cause mortality [36].

The safety outcomes were defined as hemorrhagic stroke, acute hepatitis, rhabdomyolysis, newly diagnosed dementia and newly diagnosed cancer during the period of follow-up.

\subsection{Statistical analysis}

To decrease bias due to confounding when comparing treatment effects between the ATOR 40 and EZSIM 20 groups, we conducted a propensity score matching analysis. The propensity score was the predicted probability of being the in one group given the values of covariates in the logistic regression. The selected covariates to calculate propensity score were listed in Table 1 where the follow up year was replaced with the index date. We adopted a greedy nearest neighbor algorithm with a caliper of 0.2 times the standard deviation of the logit of propensity score, with random matching order and without replacement. Matching quality was assessed using the absolute value of the standardized difference (STD) between the groups after matching, where a value lower than 0.1 represented negligible difference between the groups.

We compared the risks of all-cause mortality between the groups by using the Cox proportional hazards model. The risks of other time-to-event outcomes in the two groups were compared using the Fine and Gray subdistribution hazard model that considered death a competing risk. The within-pair clustering of outcomes after propensity score matching was accounted for by using a robust standard error (the marginal model) [37]. The unadjusted cumulative incidence function of the outcomes was calculated and

plotted under a subdistribution hazard model. The study group (ATOR 40 versus EZ-SIM 20) was the only explanatory variable in survival analyses.

A post-hoc subgroup analysis was performed to determine whether the subdistribution hazard ratios of secondary composite CV outcomes for the ATOR 40 and EZ-SIM 20 groups were similar in the subgroups. A two-sided $P$ value of less than 0.05 was considered statistically significant and no adjustment for multiple testing (multiplicity) was made in this study. All statistical analyses were performed using SAS version 9.4 (SAS Institute, Cary, NC, USA), including the procedures of 'psmatch' for PSM, 'phreg'for survival analyses, and the macro of '\%cif' for the cumulative incidence function.

\section{Results}




\subsection{Demographics and clinical characteristics}

In total, 6,959 patients with T2DM who were admitted for ACS or AIS between January 1, 2007 and December 31, 2013, were eligible for this study. Of those, 5,249 (74.4\%) patients were prescribed with ATOR 40 and 1,710 (24.6\%) ones were prescribed with EZ-SIM 20. After application of PSM with 1:1 ratio, 1,686 patients in either groups (Figure 2). After PSM, all values of absolute STD were lower than 0.1, which stands for negligible differences in demographics, comorbidities, and medications at baseline between these two groups (right panel of Table 1).

The mean follow-up period was 2.4 years (standard deviation [SD], 1.6 years) and the maximum followup duration was 6.9 years. The mean age of the patients at baseline was 66.2 years (SD, 10.6 years). The most common co-morbidity was hypertension ( $86.7 \%$ versus $87.8 \%)$, followed by dyslipidemia $(73.6 \%$ versus $74.4 \%$ ) and chronic kidney disease (33.2\% versus $33.7 \%$ ) in the ATOR 40 group and the EZ-SIM 20 group, respectively. In addition, patients with old MI and old ischemic stroke in the ATOR 40 group were 7.9 and 19.5\%, respectively; in the EZ-SIM 20 group, those with old MI and old ischemic stroke were 8.1 and $19.5 \%$, respectively (Table 1 ).

\subsection{Primary composite outcome}

The primary composite outcome occurred in 422 patients (25.0\%) in the ATOR 40 group and 398 patients $(23.6 \%)$ in the EZ-SIM 20 group (subdistribution hazard ratio [SHR], 1.09; 95\% confidence interval [CI], 0.95-1.25; Table 2; Figure 2A). Regarding the individual composite outcomes, non-significant difference of risks for CV death (SHR, 1.06; 95\% Cl, 0.85-1.32), non-fatal MI (SHR, 0.98; 95\% Cl, 0.74-1.29), and non-fatal stroke (SHR, $1.15 ; 95 \% \mathrm{Cl}, 0.96-1.38$ ) were observed between these two groups (Table 2; Figure 2B-2D).

\subsection{Secondary composite outcome and other clinical outcomes}

The secondary composite outcome occurred in 255 patients (15.1\%) in the ATOR 40 group and 326 patients (19.3\%) in the EZ-SIM 20 group (SHR, 0.77; 95\% Cl, 0.66-0.89; Table 2; Figure 3A). Patients in the ATOR 40 group had lower risks of HUA (SHR, 0.50; 95\% Cl, 0.35-0.72), PCl (SHR, 0.82; 95\% Cl, 0.69-0.97) and CABG (SHR, 0.62; 95\% Cl, 0.40-0.97) than those in the EZ-SIM 20 group (Table 2; Figure 3B-3D). The risks of HHF (SHR, $1.05 ; 95 \% \mathrm{Cl}, 0.84-1.32$ ) and all-cause mortality (hazard ratio, $1.09 ; 95 \% \mathrm{Cl}, 0.92-$ 1.28) were similar between the ATOR 40 group and the EZ-SIM 20 group (Table 2).

\subsection{Safety outcomes}

The ATOR 40 and EZ-SIM 20 groups did not differ significantly in terms of incidence of hemorrhagic stroke $(0.9 \%$ versus $1.2 \% ; P=0.323)$, acute hepatitis $(0.6 \%$ versus $0.2 \% ; P=0.118)$, rhabdomyolysis $(0.3 \%$ versus $0.5 \% ; P=0.411)$, newly diagnosed dementia ( $5.0 \%$ versus $5.2 \% ; P=0.910)$, or newly diagnosed malignancy $(4.3 \%$ versus $3.9 \% ; P=0.437)$ (Table 2$)$.

\subsection{Subgroup analysis}


There was a significant result of the secondary composite outcome between these two groups. Therefore, a post-hoc subgroup analysis was performed to evaluate whether the SHRs of the secondary composite outcome were similar in the selected subgroups. The results demonstrated that the effect of ATOR 40 did not differ significantly in the subgroups of age, gender, duration of T2DM, admitted due to ACS or AIS, heart failure, chronic kidney disease, atrial fibrillation, hypertension, and dyslipidemia (Figure 4). Noticeably, the values of all SHRs were less than 1 which favored the ATOR 40 group regardless of the statistical significance.

\section{Discussion}

In this nationwide, population-based, non-crossover and observational cohort study, we tested the hypothesis of "the pleiotropic effects of purely higher dose statin may play a role in CV benefits than a combination of ezetimibe and lower dose statin in a comparable reduction of LDL-C". Although the primary composite outcome (CV death, non-fatal MI and non-fatal stroke) was no different between the ATOR 40 group and the EZ-SIM 20 group in T2DM patients after ACS or AIS, treatment with ATOR 40 had the lower risks of $\mathrm{HUA}, \mathrm{PCl}$ and $\mathrm{CABG}$ than EZ-SIM 20 which is compatible with coronary plaque stabilization is independent of LDL-C reduction [38]. The use of ATOR 40 reduced the risk of HUA by $50 \%$, $\mathrm{PCl}$ by $18 \%$ and $\mathrm{CABG}$ by $38 \%$ with a mean follow-up of 2.4 years. For decreasing risks of $\mathrm{HUA}, \mathrm{PCl}$ and CABG, the numbers needed to treat were 41.7, 37 and 100, respectively. There was a consistent benefit of ATOR 40 versus EZ-SIM 20 on the secondary composite outcome across all subgroups.

As studies aforementioned in the section of introduction, whether statin's clinical CV benefits are partially due to its pleiotropic effects or just due to the reduction of LDL-C and even in a equal intensity of LDL-C lowering, whether purely higher dose statin is better than a combination of ezetimibe and lower dose statin are still debated; positive findings were limited to the discovery of improvements of endothelial function and vascular inflammation which could only be a surrogate marker for CV outcomes in our realworld patients. Therefore, the valuable strength of our research is that it is the first real-world and nationwide population-based cohort study to evaluate the solid CV outcomes of the pleiotropic effects of statins at the similar reduction of LDL-C and provided the evidence of the pleiotropic effects on extremely $\mathrm{CV}$ risk patients who tend to be vulnerable to the further major $\mathrm{CV}$ diseases over a relatively short period and could significantly get more cardiac benefits with the pleiotropic effects by the purely higher dose statin beyond a comparable reduction of LDL-C. In other words, our study complemented to answer the question from the IMPROVE-IT study that "We know the lower is the better but is there a different CV outcome between pure statin and ezetimibe-statin therapy when having a similar LDL-C reduction or goal?" and our answer could be yes based on reducing risks of HUA, PCl and CABG by ATOR 40 compared with EZ-SIM 20 in the present study which could imply the pleiotropic effects made these differences. Nevertheless, our results of study still supported the concept that LDL-C is a key role in the pathogenesis of ASCVD [39, 40] and the capacity of medication to lower of LDL-C regardless of statin or non-statin therapies (ezetimibe and PCSK9 inhibitors) is definitely the first concern rather than the pleiotropic effects because the primary composite outcome (CV death, non-fatal MI, and non-fatal stroke) 
in our study showed no difference between the ATOR 40 group and EZ-SIM 20 group. The similar or equivalent reduction of LDL-C brings the similarly major CV outcomes.

However, according to our data, something in detail should be more addressed as follows. Although the reduction of LDL-C of ATOR 40 is similar to EZ-SIM 20, the reduction of LDL-C by ATOR 40 is still less than that by EZ-SIM 20 numerically according to the previous data; the average reductions of LDL-C by ATOR 40 is $48.3-49 \%[14,41-43]$ but those by EZ-SIM 20 is $50.6-51.9 \%$ [14, 44, 45]. As a result, in theory, based on the concept of "the lower, the better", EZ-SIM 20 could be more effective to reduce ASCVD complications but our findings were inconsistent. For CV death and non-fatal stroke, the SHR of ATOR 40 versus EZ-SIM 20 was worse insignificantly; for non-fatal MI, HUA, PCI and CABG, the SHR of ATOR 40 versus EZ-SIM 20 were better (insignificant for SHR of non-fatal MI but significant for SHRs of $\mathrm{HUA}, \mathrm{PCl}$ and CABG. But because of the discrepancy in these findings, they highlighted the role of pleiotropic effects which could contribute to these results. The pleiotropic effects could compensate for less reductions of LDL-C by ATOR 40 and resulted in no significant differences in the primary composite outcome. Moreover, the pleiotropic effects, especially the ability for anti-inflammation may have more influence on coronary atherosclerosis than coratid atherosclerosis which is the pathogenesis of large artery ischemic stroke. The destabilization of atherosclerotic lesions due to systemic inflammatory could lead to the plaques rupture and subsequent thrombosis. The levels of hs-CRP level are associated with higher risks for coronary atherosclerosis but not for carotid atherosclerosis [46]. ATOR 40 could lower hsCRP more than EZ-SIM 20 [14]. Besides, the plaque instability due to increased intracellular adhesion molecule-1 (ICAM-1) has been noted in coronary atherosclerosis but not in carotid atherosclerosis [47]. Higher dose of statins may decrease more ICAM-1 [48]. As a result, our study showed patients in the ATOR 40 group may get more cardiac benefits particularly without decreasing stroke events than those in the EZ-SIM 20 group.

\subsection{Limitation}

Our present study has some limitations. First, the record of smoking was lacking in the NHIRD database and smoking is an important confounding factor of CV outcomes. Therefore, chronic obstructive pulmonary disease (COPD) was used as a proxy variable instead of smoking for matching at baseline to mitigate this important confounding factor because smoking is strongly associated with the prevalence of COPD [49]. Second, because the lab data in the NHIRD database were not available, the actual effects of lipid-lowering agents were unknown and the patients could only be assumed to have theoretically therapeutic effects based on previous literatures. Finally, unfortunately in this claim database study, we had difficulty in clarifying the subtypes of the upcoming ischemic stroke. Because the strong association between cholesterol and carotid atherosclerosis supporting that cholesterol is a main pathogenesis of the large artery ischemic stroke, the large artery ischemic stroke is one subtype of ischemic strokes that could be proven to get benefits from statins treatment. This may limit the further discussion of the pleiotropic effects on stroke events because the beneficial effects of statins therapy on the other subtypes of ischemic stroke are less certain. 
In spite of these limitations, our real-world and nationwide population-based cohort study is still valuable to answer the uncertain question and to fill the gap of evidence of pleiotropic effects by purely higher dose statin on $\mathrm{CV}$ outcomes beyond a comparable reduction of LDL-C.

\subsection{Conclusions}

In summary, the pleiotropic effects could play a role on cardiac benefits with lowering risks of HUA, PCI and CABG beyond a similar reduction of LDL-C. For more cardiac benefits of T2DM patients after a recent ACS or AIS, ATOR 40 could be considered prior to EZ-SIM 20 to achieve the reduction of LDL-C $\geq 50 \%$ or the goal of LDL-C and this kind of clinical practice is in line with the concept of current clinical practice guidelines which suggest ezetimibe should be added to statins when patients do not achieve the reduction of LDL-C $\geq 50 \%$ or the goal of LDL-C after a maximal and tolerable intensification of statins therapy.

\section{Declarations}

\section{Ethics approval and consent to participate}

The protocol of this study and informed consent of all participants were approved by the Ethics Institutional Review Board of Chang Gung Memorial Hospital.

\section{Consent for publication}

Authors give full consents for publication of this present article.

\section{Availability of data and materials}

This datasets used and analyzed in this study are available from the corresponding author on reasonable requests.

\section{Competing interests}

The authors report no financial relationships or conflicts of interest regarding the content herein.

\section{Funding}

This work was supported by grants from the Chang Gung Memorial Hospital, Taiwan (CMRPG3H1261, CGRPG2F0011, CLRPG2C0021, CLRPG2C0022, CLRPG2C0023, CLRPG2C0024, CLRPG2G0081, CLRPG2G0082 and CLRPG2H0041).

\section{Author's contributions}

Authors contributions are as follows: (1) study conception and design (Yan-Rong Li, Yu-Cheng Kao, ChiHung Liu, Tien-Hsing Chen); (2) drafting of the manuscript (Yan-Rong Li, Yu-Cheng Kao, Tien-Hsing Chen, 
Chi-Hung Liu); (3) data analysis and interpretation (Yan-Rong Li, Yu-Cheng Kao, Chi-Hung Liu, ChingChung Hsiao, Jawl-Shan Hwang, Yu-Sheng Lin, Chun-Tai Mao, Ming-Jui Hung, Tien-Hsing Chen).

\section{Acknowledgements}

We thank Alfred Hsing-Fen Lin and Ben Yu-Lin Chou for their statistical assistance during the composition of this manuscript.

\section{References}

1. Haffner SM, Lehto S, Ronnemaa T, Pyorala K, Laakso M. Mortality from coronary heart disease in subjects with type 2 diabetes and in nondiabetic subjects with and without prior myocardial infarction. N Engl J Med. 1998;339:229-34.

2. Rawshani A, Rawshani A, Franzen S, et al. Risk Factors, Mortality, and Cardiovascular Outcomes in Patients with Type 2 Diabetes. N Engl J Med. 2018;379:633-44.

3. Boccara F, Cohen A. Interplay of diabetes and coronary heart disease on cardiovascular mortality. Heart. 2004;90:1371-3.

4. Shou J, Zhou L, Zhu S, Zhang X. Diabetes is an Independent Risk Factor for Stroke Recurrence in Stroke Patients: A Meta-analysis. J Stroke Cerebrovasc Dis. 2015;24:1961-8.

5. Garber AJ, Abrahamson MJ, Barzilay JI, et al. CONSENSUS STATEMENT BY THE AMERICAN ASSOCIATION OF CLINICAL ENDOCRINOLOGISTS AND AMERICAN COLLEGE OF ENDOCRINOLOGY ON THE COMPREHENSIVE TYPE 2 DIABETES MANAGEMENT ALGORITHM - 2019 EXECUTIVE SUMMARY. Endocr Pract. 2019;25:69-100.

6. Li YH, Ueng KC, Jeng JS, et al. 2017 Taiwan lipid guidelines for high risk patients. J Formos Med Assoc. 2017;116:217-248.

7. Grundy SM, Stone NJ, Bailey AL, et al. 2018 AHA/ACC/AACVPR/AAPA/ABC/ACPM/ADA/AGS/APhA/ASPC/NLA/PCNA Guideline on the Management of Blood Cholesterol: A Report of the American College of Cardiology/American Heart Association Task Force on Clinical Practice Guidelines. J Am Coll Cardiol. 2018.

8. 10. Cardiovascular Disease and Risk Management: Standards of Medical Care in Diabetes-2019. Diabetes care. 2019;42:S103-23.

9. Cannon CP, Blazing MA, Giugliano RP, et al. Ezetimibe Added to Statin Therapy after Acute Coronary Syndromes. N Engl J Med. 2015;372:2387-97.

10. Ouchi Y. Ezetimibe in Prevention of Cerebro- and Cardiovascular Events in Middle- to High-Risk, Elderly (75 Years Old or Over) Patients With Elevated LDL-Cholesterol - EWTOPIA 75. American Heart Association Annual Scientific Sessions (AHA 2018), Chicago, IL.

11. Schwartz GG, Steg PG, Szarek M, et al. Alirocumab and Cardiovascular Outcomes after Acute Coronary Syndrome. N Engl J Med. 2018;379:2097-107. 
12. Sabatine MS, Giugliano RP, Keech AC, et al. Evolocumab and Clinical Outcomes in Patients with Cardiovascular Disease. N Engl J Med. 2017;376:1713-22.

13. Stone NJ, Robinson JG, Lichtenstein AH, et al. 2013 ACC/AHA guideline on the treatment of blood cholesterol to reduce atherosclerotic cardiovascular risk in adults: a report of the American College of Cardiology/American Heart Association Task Force on Practice Guidelines. Circulation. 2014;129:S145.

14. Ballantyne CM, Abate N, Yuan Z, King TR, Palmisano J. Dose-comparison study of the combination of ezetimibe and simvastatin (Vytorin) versus atorvastatin in patients with hypercholesterolemia: the Vytorin Versus Atorvastatin (VYVA) study. Am Heart J. 2005;149:464-73.

15. Galin ID, Smith DA. Dose-comparison study of the combination of ezetimibe and simvastatin (Vytorin) versus atorvastatin in patients with hypercholesterolemia: the Vytorin Versus Atorvastatin (VYVA) Study. Am Heart J. 2006;151:e1.

16. Masana L, Pedro-Botet J, Civeira F. IMPROVE-IT clinical implications. Should the "high-intensity cholesterol-lowering therapy" strategy replace the "high-intensity statin therapy"? Atherosclerosis. 2015;240:161-2.

17. Liao JK, Laufs U. Pleiotropic effects of statins. Annu Rev Pharmacol toxicol. 2005;45:89-118.

18. Oesterle A, Laufs U, Liao JK. Pleiotropic Effects of Statins on the Cardiovascular System. Circ Res. 2017;120:229-43.

19. Oesterle A, Liao JK. The Pleiotropic Effects of Statins - From Coronary Artery Disease and Stroke to Atrial Fibrillation and Ventricular Tachyarrhythmia. Curr Vasc Pharmacol. 2019;17:222-32.

20. Liu PY, Liu YW, Lin LJ, Chen JH, Liao JK. Evidence for statin pleiotropy in humans: differential effects of statins and ezetimibe on rho-associated coiled-coil containing protein kinase activity, endothelial function, and inflammation. Circulation. 2009;119:131-8.

21. Fichtlscherer S, Schmidt-Lucke C, Bojunga S, et al. Differential effects of short-term lipid lowering with ezetimibe and statins on endothelial function in patients with CAD: clinical evidence for 'pleiotropic' functions of statin therapy. Eur Heart J. 2006;27:1182-90.

22. Rudofsky G, Reismann P, Groener JB, et al. Identical LDL-cholesterol lowering but non-identical effects on NF-kappaB activity: High dose simvastatin vs combination therapy with ezetimibe. Atherosclerosis. 2012;223:190-6.

23. Matsue Y, Matsumura A, Suzuki M, Hashimoto Y, Yoshida M. Differences in action of atorvastatin and ezetimibe in lowering low-density lipoprotein cholesterol and effect on endothelial function: randomized controlled trial. Circ J. 2013;77:1791-8.

24. Kawagoe Y, Hattori Y, Nakano A, et al. Comparative study between high-dose fluvastatin and lowdose fluvastatin and ezetimibe with regard to the effect on endothelial function in diabetic patients. Endocr J. 2011;58:171-5.

25. Pesaro AE, Serrano CV Jr, Fernandes JL, et al. Pleiotropic effects of ezetimibe/simvastatin vs. high dose simvastatin. Int J Cardiol. 2012;158:400-4. 
26. Westerink J, Deanfield JE, Imholz BP, et al. High-dose statin monotherapy versus low-dose statin/ezetimibe combination on fasting and postprandial lipids and endothelial function in obese patients with the metabolic syndrome: The PANACEA study. Atherosclerosis. 2013;227:118-24.

27. Hsieh CY, Chen $\mathrm{CH}$, Li CY, Lai ML. Validating the diagnosis of acute ischemic stroke in a National Health Insurance claims database. J Formos Med Assoc. 2015;114:254-9.

28. Chang $\mathrm{CH}$, Lee YC, Tsai CT, et al. Continuation of statin therapy and a decreased risk of atrial fibrillation/flutter in patients with and without chronic kidney disease. Atherosclerosis. 2014;232:22430.

29. Cheng CL, Lee $\mathrm{CH}$, Chen PS, Li YH, Lin SJ, Yang YH. Validation of acute myocardial infarction cases in the national health insurance research database in taiwan. J Epidemiol. 2014;24:500-7.

30. Cheng CL, Kao YH, Lin SJ, Lee CH, Lai ML. Validation of the National Health Insurance Research Database with ischemic stroke cases in Taiwan. Pharmacoepidemiol Drug Saf. 2011;20:236-42.

31. Hsing AW, loannidis JP. Nationwide Population Science: Lessons From the Taiwan National Health Insurance Research Database. JAMA Intern Med. 2015;175:1527-9.

32. Liu CH, Chen TH, Lin MS, et al. Ezetimibe-Simvastatin Therapy Reduce Recurrent Ischemic Stroke Risks in Type 2 Diabetic Patients. J Clin Endocrinol Metab. 2016;101:2994-3001.

33. Li YR, Tsai SS, Lin YS, et al. Moderate- to high-intensity statins for secondary prevention in patients with type 2 diabetes mellitus on dialysis after acute myocardial infarction. Diabetol Metab Syndr. 2017;9:71.

34. Chung $\mathrm{CM}$, Lin MS, Chang $\mathrm{CH}$, et al. Moderate to high intensity statin in dialysis patients after acute myocardial infarction: A national cohort study in Asia. Atherosclerosis. 2017;267:158-66.

35. Lin CC, Lai MS, Syu CY, Chang SC, Tseng FY. Accuracy of diabetes diagnosis in health insurance claims data in Taiwan. J Formos Med Assoc. 2005;104:157-63.

36. Cheng CL, Chien HC, Lee CH, Lin SJ, Yang YH. Validity of in-hospital mortality data among patients with acute myocardial infarction or stroke in National Health Insurance Research Database in Taiwan. Int J Cardiol. 2015;201:96-101.

37. Austin PC, Fine JP. Propensity-score matching with competing risks in survival analysis. Stat Med. 2019;38:751-77.

38. Libby P, Sasiela W. Plaque stabilization: Can we turn theory into evidence? Am J Cardiol. 2006;98:26P-33P.

39. Mendis S, Davis S, Norrving B. Organizational update: the world health organization global status report on noncommunicable diseases 2014; one more landmark step in the combat against stroke and vascular disease. Stroke. 2015;46:e121-2.

40. Ference BA, Majeed F, Penumetcha R, Flack JM, Brook RD. Effect of naturally random allocation to lower low-density lipoprotein cholesterol on the risk of coronary heart disease mediated by polymorphisms in NPC1L1, HMGCR, or both: a 2 x 2 factorial Mendelian randomization study. J Am Coll Cardiol. 2015;65:1552-61. 
41. Nawrocki JW, Weiss SR, Davidson MH, et al. Reduction of LDL cholesterol by $25 \%$ to $60 \%$ in patients with primary hypercholesterolemia by atorvastatin, a new HMG-CoA reductase inhibitor. Arterioscler Thromb Vasc Biol. 1995;15:678-82.

42. Adams SP, Tsang M, Wright JM. Lipid-lowering efficacy of atorvastatin. Cochrane Database Syst Rev. 2015:CD008226.

43. Collins R, Reith C, Emberson J, et al. Interpretation of the evidence for the efficacy and safety of statin therapy. Lancet. 2016;388:2532-61.

44. Bays HE, Ose L, Fraser N, et al. A multicenter, randomized, double-blind, placebo-controlled, factorial design study to evaluate the lipid-altering efficacy and safety profile of the ezetimibe/simvastatin tablet compared with ezetimibe and simvastatin monotherapy in patients with primary hypercholesterolemia. Clin Ther. 2004;26:1758-73.

45. Catapano AL, Davidson MH, Ballantyne CM, et al. Lipid-altering efficacy of the ezetimibe/simvastatin single tablet versus rosuvastatin in hypercholesterolemic patients. Curr Med Res Opin. 2006;22:204153.

46. Choi H, Cho DH, Shin HH, Park JB. Association of high sensitivity C-reactive protein with coronary heart disease prediction, but not with carotid atherosclerosis, in patients with hypertension. Circ $\mathrm{J}$. 2004;68:297-303.

47. Jashari F, Ibrahimi P, Nicoll R, Bajraktari G, Wester P, Henein MY. Coronary and carotid atherosclerosis: similarities and differences. Atherosclerosis. 2013;227:193-200.

48. Blanco-Colio LM, Martin-Ventura JL, de Teresa E, et al. Elevated ICAM-1 and MCP-1 plasma levels in subjects at high cardiovascular risk are diminished by atorvastatin treatment. Atorvastatin on Inflammatory Markers study: a substudy of Achieve Cholesterol Targets Fast with Atorvastatin Stratified Titration. Am Heart J. 2007;153:881-8.

49. Pauwels RA, Rabe KF. Burden and clinical features of chronic obstructive pulmonary disease (COPD). Lancet. 2004;364:613-20.

\section{Tables}


Table 1

Characteristics of the study patients before and after propensity score matching

Data before matching

$\begin{array}{llllll}\text { ATOR } 40 & \text { EZ-SIM } & \text { STD } & \text { ATOR } & \text { EZ-SIM } & \text { STD } \\ (n= & 20 & & 40 & 20 & \\ 5,249) & (n= & & (n= & (n= & \\ & 1,710) & & 1,686) & 1,686) & \end{array}$

Etiology

$\begin{array}{lllllll}\text { ACS } & 2,118 & 594 & 0.12 & 591 & 591 & < \\ & (40.4) & (34.7) & & (35.1) & (35.1) & 0.01 \\ \text { AIS } & 3,131 & 1,116 & -0.12 & 1,095 & 1,095 & < \\ & (59.6) & (65.3) & & (64.9) & (64.9) & 0.01 \\ \text { Age at index date, years } & 66.4 \pm & 66.1 \pm & 0.03 & 66.3 \pm & 66.1 \pm & 0.02 \\ & 10.6 & 10.5 & & 10.7 & 10.5 & \end{array}$

Age group

40-64 years.

65-74 years.

75-84 years.

$\geq 85$ years.

Gender

Male

Female

DM duration, years
2,368

(45.1)

1,668

(31.8)

1,049

(20.0)

164

(3.1)

2,932

(55.9)

892

(52.2)

2,317

(44.1)

\section{8}

(46.1)

540

(31.6)

341

(19.9)

41 (2.4)

818

(47.8)

$9.7 \pm 3.5$
$-0.02$

$<$

0.01

$<$

0.01

0.04

0.07

$-0.07$

$-0.24$
Data after matching
10.5
$10.5 \pm$

3.6

DM duration group

Abbreviation: ATOR 40, atorvastatin $40 \mathrm{mg}$; EZ-SIM 20, ezetimibe $10 \mathrm{mg} /$ simvastatin $20 \mathrm{mg}$; STD, standardized difference; ACS, acute coronary syndrome; AIS, acute ischemic stroke; DM, diabetes mellitus; VTE, venous thromboembolism; PE, pulmonary embolism; DVT, deep vein thrombosis; HBV, hepatitis B virus; $\mathrm{HCV}$, hepatitis C virus; NOAC, novel oral anticoagulant; $\mathrm{ACEl}$, angiotensin-convertingenzyme inhibitor; ARB, angiotensin receptor blocker; CCB, calcium channel blocker; NSAID, nonsteroidal anti-inflammatory drug; COX-2, cyclo-oxygenase-2; DPP-4, dipeptidyl peptidase-4

Data were presented as frequency and percentage or mean \pm standard deviation. 


\begin{tabular}{|c|c|c|c|c|c|c|}
\hline \multirow[b]{2}{*}{$0-5$ years } & \multicolumn{3}{|c|}{ Data before matching } & \multicolumn{3}{|c|}{ Data after matching } \\
\hline & $\begin{array}{l}843 \\
(16.1)\end{array}$ & $\begin{array}{l}206 \\
(12.0)\end{array}$ & 0.12 & $\begin{array}{l}198 \\
(11.7)\end{array}$ & $\begin{array}{l}204 \\
(12.1)\end{array}$ & -0.01 \\
\hline $6-10$ years & $\begin{array}{l}2,382 \\
(45.4)\end{array}$ & $\begin{array}{l}603 \\
(35.3)\end{array}$ & 0.21 & $\begin{array}{l}621 \\
(36.8)\end{array}$ & $\begin{array}{l}602 \\
(35.7)\end{array}$ & 0.02 \\
\hline $11-15$ years & $\begin{array}{l}1,977 \\
(37.7)\end{array}$ & $\begin{array}{l}863 \\
(50.5)\end{array}$ & -0.26 & $\begin{array}{l}835 \\
(49.5)\end{array}$ & $\begin{array}{l}846 \\
(50.2)\end{array}$ & -0.01 \\
\hline$\geq 16$ years & $47(0.9)$ & $38(2.2)$ & -0.11 & $32(1.9)$ & $34(2.0)$ & -0.01 \\
\hline $\begin{array}{l}\text { No. of outpatient DM visit in } \\
\text { previous year }\end{array}$ & $\begin{array}{l}13.6 \pm \\
8.8\end{array}$ & $\begin{array}{l}14.1 \pm \\
9.4\end{array}$ & -0.05 & $\begin{array}{l}13.8 \pm \\
8.7\end{array}$ & $\begin{array}{l}14.0 \pm \\
9.3\end{array}$ & -0.03 \\
\hline $\begin{array}{l}\text { HbA1c exam in the previous } \\
\text { year }\end{array}$ & $2.4 \pm 1.9$ & $2.7 \pm 2.0$ & -0.17 & $2.6 \pm 2.0$ & $2.7 \pm 2.0$ & -0.04 \\
\hline \multicolumn{7}{|l|}{ History of event } \\
\hline Previous ischemic stroke & $\begin{array}{l}956 \\
(18.2)\end{array}$ & $\begin{array}{l}333 \\
(19.5)\end{array}$ & -0.03 & $\begin{array}{l}328 \\
(19.5)\end{array}$ & $\begin{array}{l}328 \\
(19.5)\end{array}$ & $\begin{array}{l}< \\
0.01\end{array}$ \\
\hline Old myocardial infarction & $\begin{array}{l}372 \\
(7.1)\end{array}$ & $\begin{array}{l}141 \\
(8.2)\end{array}$ & -0.04 & $\begin{array}{l}133 \\
(7.9)\end{array}$ & $\begin{array}{l}136 \\
(8.1)\end{array}$ & -0.01 \\
\hline Heart failure & $\begin{array}{l}594 \\
(11.3)\end{array}$ & $\begin{array}{l}201 \\
(11.8)\end{array}$ & -0.01 & $\begin{array}{l}210 \\
(12.5)\end{array}$ & $\begin{array}{l}197 \\
(11.7)\end{array}$ & 0.02 \\
\hline VTE: PE or DV & $37(0.7)$ & $21(1.2)$ & -0.05 & $18(1.1)$ & $19(1.1)$ & -0.01 \\
\hline \multicolumn{7}{|l|}{ Comorbidity } \\
\hline \multicolumn{7}{|l|}{ Chronic kidney disease (CKD) } \\
\hline None & $\begin{array}{l}3,735 \\
(71.2)\end{array}$ & $\begin{array}{l}1,126 \\
(65.8)\end{array}$ & 0.11 & $\begin{array}{l}1,126 \\
(66.8)\end{array}$ & $\begin{array}{l}1,117 \\
(66.3)\end{array}$ & 0.01 \\
\hline Non-dialysis CKD & $\begin{array}{l}1,277 \\
(24.3)\end{array}$ & $\begin{array}{l}512 \\
(29.9)\end{array}$ & -0.13 & $\begin{array}{l}489 \\
(29.0)\end{array}$ & $\begin{array}{l}498 \\
(29.5)\end{array}$ & -0.01 \\
\hline Dialysis & $\begin{array}{l}237 \\
(4.5)\end{array}$ & $72(4.2)$ & 0.01 & $71(4.2)$ & $71(4.2)$ & $<0$. \\
\hline Gout & $\begin{array}{l}471 \\
(9.0)\end{array}$ & $\begin{array}{l}161 \\
(9.4)\end{array}$ & -0.02 & $\begin{array}{l}142 \\
(8.4)\end{array}$ & $\begin{array}{l}158 \\
(9.4)\end{array}$ & -0.03 \\
\hline
\end{tabular}

Abbreviation: ATOR 40, atorvastatin $40 \mathrm{mg}$; EZ-SIM 20, ezetimibe $10 \mathrm{mg} /$ simvastatin $20 \mathrm{mg}$; STD, standardized difference; ACS, acute coronary syndrome; AIS, acute ischemic stroke; DM, diabetes mellitus; VTE, venous thromboembolism; PE, pulmonary embolism; DVT, deep vein thrombosis; HBV, hepatitis B virus; $\mathrm{HCV}$, hepatitis C virus; NOAC, novel oral anticoagulant; $\mathrm{ACEl}$, angiotensin-convertingenzyme inhibitor; ARB, angiotensin receptor blocker; CCB, calcium channel blocker; NSAID, nonsteroidal anti-inflammatory drug; COX-2, cyclo-oxygenase-2; DPP-4, dipeptidyl peptidase-4

Data were presented as frequency and percentage or mean \pm standard deviation. 


\begin{tabular}{|c|c|c|c|c|c|c|}
\hline \multirow[b]{2}{*}{ Atrial fibrillation } & \multicolumn{3}{|c|}{ Data before matching } & \multicolumn{3}{|c|}{ Data after matching } \\
\hline & $\begin{array}{l}306 \\
(5.8)\end{array}$ & $98(5.7)$ & $\dot{<} 01$ & $98(5.8)$ & $98(5.8)$ & $<.01$ \\
\hline Peripheral arterial disease & $\begin{array}{l}267 \\
(5.1)\end{array}$ & $\begin{array}{l}101 \\
(5.9)\end{array}$ & -0.04 & $90(5.3)$ & $99(5.9)$ & -0.02 \\
\hline Hypertension & $\begin{array}{l}4,497 \\
(85.7)\end{array}$ & $\begin{array}{l}1,503 \\
(87.9)\end{array}$ & -0.07 & $\begin{array}{l}1,461 \\
(86.7)\end{array}$ & $\begin{array}{l}1,480 \\
(87.8)\end{array}$ & -0.03 \\
\hline Dyslipidemia & $\begin{array}{l}3,649 \\
(69.5)\end{array}$ & $\begin{array}{l}1,274 \\
(74.5)\end{array}$ & -0.11 & $\begin{array}{l}1,241 \\
(73.6)\end{array}$ & $\begin{array}{l}1,254 \\
(74.4)\end{array}$ & -0.02 \\
\hline $\begin{array}{l}\text { Chronic obstructive pulmonary } \\
\text { disease }\end{array}$ & $\begin{array}{l}344 \\
(6.6)\end{array}$ & $\begin{array}{l}114 \\
(6.7)\end{array}$ & $\stackrel{<}{<.01}$ & $\begin{array}{l}110 \\
(6.5)\end{array}$ & $\begin{array}{l}112 \\
(6.6)\end{array}$ & $<$. \\
\hline Malignancy & $\begin{array}{l}255 \\
(4.9)\end{array}$ & $97(5.7)$ & -0.04 & $93(5.5)$ & $96(5.7)$ & -0.01 \\
\hline Cirrhosis & $45(0.9)$ & $9(0.5)$ & 0.04 & $5(0.3)$ & $9(0.5)$ & -0.04 \\
\hline HBV infection & $68(1.3)$ & $17(1.0)$ & 0.03 & $16(0.9)$ & $17(1.0)$ & -0.01 \\
\hline HCV infection & $61(1.2)$ & $21(1.2)$ & -0.01 & $24(1.4)$ & $21(1.2)$ & 0.02 \\
\hline Alcoholism & $33(0.6)$ & $8(0.5)$ & 0.02 & $6(0.4)$ & $8(0.5)$ & -0.02 \\
\hline Autoimmune disease & $71(1.4)$ & $30(1.8)$ & -0.03 & $31(1.8)$ & $29(1.7)$ & 0.01 \\
\hline Previous coronary intervention & $\begin{array}{l}690 \\
(13.1)\end{array}$ & $\begin{array}{l}297 \\
(17.4)\end{array}$ & -0.12 & $\begin{array}{l}270 \\
(16.0)\end{array}$ & $\begin{array}{l}289 \\
(17.1)\end{array}$ & -0.03 \\
\hline \multicolumn{7}{|l|}{ Non-DM medication } \\
\hline Aspirin & $\begin{array}{l}4,803 \\
(91.5)\end{array}$ & $\begin{array}{l}1,526 \\
(89.2)\end{array}$ & 0.08 & $\begin{array}{l}1,532 \\
(90.9)\end{array}$ & $\begin{array}{l}1,506 \\
(89.3)\end{array}$ & 0.05 \\
\hline Clopidogrel & $\begin{array}{l}2,608 \\
(49.7)\end{array}$ & $\begin{array}{l}755 \\
(44.2)\end{array}$ & 0.11 & $\begin{array}{l}739 \\
(43.8)\end{array}$ & $\begin{array}{l}746 \\
(44.2)\end{array}$ & -0.01 \\
\hline $\begin{array}{l}\text { Anticoagulant (Warfarin or } \\
\text { NOAC) }\end{array}$ & $\begin{array}{l}293 \\
(5.6)\end{array}$ & $82(4.8)$ & 0.04 & $75(4.4)$ & $82(4.9)$ & -0.02 \\
\hline ACEI/ARB & $\begin{array}{l}3,768 \\
(71.8)\end{array}$ & $\begin{array}{l}1,238 \\
(72.4)\end{array}$ & -0.01 & $\begin{array}{l}1,230 \\
(73.0)\end{array}$ & $\begin{array}{l}1,220 \\
(72.4)\end{array}$ & 0.01 \\
\hline
\end{tabular}

Abbreviation: ATOR 40, atorvastatin $40 \mathrm{mg}$; EZ-SIM 20, ezetimibe $10 \mathrm{mg} / \mathrm{simvastatin} 20 \mathrm{mg}$; STD, standardized difference; ACS, acute coronary syndrome; AIS, acute ischemic stroke; DM, diabetes mellitus; VTE, venous thromboembolism; PE, pulmonary embolism; DVT, deep vein thrombosis; HBV, hepatitis B virus; $\mathrm{HCV}$, hepatitis $\mathrm{C}$ virus; NOAC, novel oral anticoagulant; ACEl, angiotensin-convertingenzyme inhibitor; ARB, angiotensin receptor blocker; CCB, calcium channel blocker; NSAID, nonsteroidal anti-inflammatory drug; COX-2, cyclo-oxygenase-2; DPP-4, dipeptidyl peptidase-4

Data were presented as frequency and percentage or mean \pm standard deviation. 


\begin{tabular}{|c|c|c|c|c|c|c|}
\hline \multirow[b]{2}{*}{$\beta$-blocker } & \multicolumn{3}{|c|}{ Data before matching } & \multicolumn{3}{|c|}{ Data after matching } \\
\hline & $\begin{array}{l}2,559 \\
(48.8)\end{array}$ & $\begin{array}{l}795 \\
(46.5)\end{array}$ & 0.05 & $\begin{array}{l}776 \\
(46.0)\end{array}$ & $\begin{array}{l}785 \\
(46.6)\end{array}$ & -0.01 \\
\hline CCB & $\begin{array}{l}2,718 \\
(51.8)\end{array}$ & $\begin{array}{l}887 \\
(51.9)\end{array}$ & $\dot{0}_{0.01}$ & $\begin{array}{l}885 \\
(52.5)\end{array}$ & $\begin{array}{l}875 \\
(51.9)\end{array}$ & 0.01 \\
\hline Digoxin & $\begin{array}{l}212 \\
(4.0)\end{array}$ & $62(3.6)$ & 0.02 & $75(4.4)$ & $62(3.7)$ & 0.04 \\
\hline NSAID/COX-2 inhibitor & $\begin{array}{l}1,272 \\
(24.2)\end{array}$ & $\begin{array}{l}461 \\
(27.0)\end{array}$ & -0.06 & $\begin{array}{l}442 \\
(26.2)\end{array}$ & $\begin{array}{l}452 \\
(26.8)\end{array}$ & -0.01 \\
\hline Diuretic & $\begin{array}{l}1,149 \\
(21.9)\end{array}$ & $\begin{array}{l}384 \\
(22.5)\end{array}$ & -0.01 & $\begin{array}{l}390 \\
(23.1)\end{array}$ & $\begin{array}{l}377 \\
(22.4)\end{array}$ & 0.02 \\
\hline Spironolactone & $\begin{array}{l}452 \\
(8.6)\end{array}$ & $\begin{array}{l}115 \\
(6.7)\end{array}$ & 0.07 & $\begin{array}{l}125 \\
(7.4)\end{array}$ & $\begin{array}{l}115 \\
(6.8)\end{array}$ & 0.02 \\
\hline Fibrate & $\begin{array}{l}225 \\
(4.3)\end{array}$ & $\begin{array}{l}159 \\
(9.3)\end{array}$ & -0.20 & $\begin{array}{l}138 \\
(8.2)\end{array}$ & $\begin{array}{l}144 \\
(8.5)\end{array}$ & -0.01 \\
\hline \multicolumn{7}{|l|}{ Hypoglycemic drugs } \\
\hline Biguanide & $\begin{array}{l}2,873 \\
(54.7)\end{array}$ & $\begin{array}{l}851 \\
(49.8)\end{array}$ & 0.10 & $\begin{array}{l}863 \\
(51.2)\end{array}$ & $\begin{array}{l}843 \\
(50.0)\end{array}$ & 0.02 \\
\hline Sulfonylurea & $\begin{array}{l}2,959 \\
(56.4)\end{array}$ & $\begin{array}{l}833 \\
(48.7)\end{array}$ & 0.15 & $\begin{array}{l}849 \\
(50.4)\end{array}$ & $\begin{array}{l}827 \\
(49.1)\end{array}$ & 0.03 \\
\hline Thiazolidinedione & $\begin{array}{l}453 \\
(8.6)\end{array}$ & $\begin{array}{l}201 \\
(11.8)\end{array}$ & -0.10 & $\begin{array}{l}192 \\
(11.4)\end{array}$ & $\begin{array}{l}194 \\
(11.5)\end{array}$ & $\dot{0} 01$ \\
\hline Alpha-glucosidase & $\begin{array}{l}954 \\
(18.2)\end{array}$ & $\begin{array}{l}289 \\
(16.9)\end{array}$ & 0.03 & $\begin{array}{l}275 \\
(16.3)\end{array}$ & $\begin{array}{l}287 \\
(17.0)\end{array}$ & -0.02 \\
\hline $\begin{array}{l}\text { Non-SU insulin secretagogue } \\
\text { (Glinide) }\end{array}$ & $\begin{array}{l}795 \\
(15.1)\end{array}$ & $\begin{array}{l}265 \\
(15.5)\end{array}$ & -0.01 & $\begin{array}{l}265 \\
(15.7)\end{array}$ & $\begin{array}{l}262 \\
(15.5)\end{array}$ & 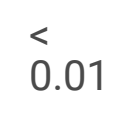 \\
\hline Insulin & $\begin{array}{l}2,893 \\
(55.1)\end{array}$ & $\begin{array}{l}886 \\
(51.8)\end{array}$ & 0.07 & $\begin{array}{l}862 \\
(51.1)\end{array}$ & $\begin{array}{l}873 \\
(51.8)\end{array}$ & -0.01 \\
\hline DPP-4 inhibitor & $\begin{array}{l}897 \\
(17.1)\end{array}$ & $\begin{array}{l}512 \\
(29.9)\end{array}$ & -0.31 & $\begin{array}{l}499 \\
(29.6)\end{array}$ & $\begin{array}{l}495 \\
(29.4)\end{array}$ & 0.01 \\
\hline \multicolumn{7}{|c|}{$\begin{array}{l}\text { Abbreviation: ATOR 40, atorvastatin } 40 \text { mg; EZ-SIM 20, ezetimibe } 10 \mathrm{mg} / \text { simvastatin } 20 \mathrm{mg} \text {; STD, } \\
\text { standardized difference; ACS, acute coronary syndrome; AIS, acute ischemic stroke; DM, diabetes } \\
\text { mellitus; VTE, venous thromboembolism; PE, pulmonary embolism; DVT, deep vein thrombosis; HBV, } \\
\text { hepatitis B virus; HCV, hepatitis C virus; NOAC, novel oral anticoagulant; ACEl, angiotensin-converting- } \\
\text { enzyme inhibitor; ARB, angiotensin receptor blocker; CCB, calcium channel blocker; NSAID, non- } \\
\text { steroidal anti-inflammatory drug; COX-2, cyclo-oxygenase-2; DPP-4, dipeptidyl peptidase-4 }\end{array}$} \\
\hline
\end{tabular}


Table 2

Clinical outcomes between the study cohorts

\begin{tabular}{|c|c|c|c|c|}
\hline Variable & $\begin{array}{l}\text { ATOR } 40 \\
(n=1,686)\end{array}$ & $\begin{array}{l}\text { EZ-SIM } 20 \\
(n=1,686)\end{array}$ & HR or SHR $(95 \% \mathrm{Cl})$ & $P$ value \\
\hline Primary composite outcome & $422(25.0)$ & $398(23.6)$ & $1.09(0.95-1.25)$ & 0.207 \\
\hline CV death & $160(9.5)$ & $152(9.0)$ & $1.06(0.85-1.32)$ & 0.596 \\
\hline Non-fatal myocardial infarction & $97(5.8)$ & $100(5.9)$ & $0.98(0.74-1.29)$ & 0.861 \\
\hline Non-fatal stroke & $225(13.3)$ & $200(11.9)$ & $1.15(0.96-1.38)$ & 0.134 \\
\hline Secondary composite outcome & $255(15.1)$ & $326(19.3)$ & $0.77(0.66-0.89)$ & $<0.001$ \\
\hline Hospitalization for unstable angina & $42(2.5)$ & $82(4.9)$ & $0.50(0.35-0.72)$ & $<0.001$ \\
\hline $\mathrm{PCl}$ & $215(12.8)$ & $261(15.5)$ & $0.82(0.69-0.97)$ & 0.020 \\
\hline CABG & $28(1.7)$ & $45(2.7)$ & $0.62(0.40-0.97)$ & 0.038 \\
\hline \multicolumn{5}{|l|}{ Other secondary outcomes } \\
\hline All-cause mortality & $292(17.3)$ & $273(16.2)$ & $1.09(0.92-1.28)$ & 0.324 \\
\hline Hospitalization for heart failure & $145(8.6)$ & $138(8.2)$ & $1.05(0.84-1.32)$ & 0.676 \\
\hline \multicolumn{5}{|l|}{ Safety outcomes } \\
\hline Hemorrhagic stroke & $15(0.9)$ & $21(1.2)$ & $0.72(0.38-1.38)$ & 0.323 \\
\hline Acute hepatitis & $10(0.6)$ & $4(0.2)$ & $2.52(0.79-8.02)$ & 0.118 \\
\hline Rhabdomyolysis & $5(0.3)$ & $8(0.5)$ & $0.63(0.21-1.91)$ & 0.411 \\
\hline New diagnosed dementia & $85(5.0)$ & $87(5.2)$ & $0.98(0.73-1.33)$ & 0.910 \\
\hline New diagnosed malignancy & $73(4.3)$ & $65(3.9)$ & $1.14(0.82-1.57)$ & 0.437 \\
\hline \multicolumn{5}{|c|}{$\begin{array}{l}\text { Abbreviation: ATOR 40, atorvastatin } 40 \mathrm{mg} \text {; EZ-SIM 20, ezetimibe } 10 \mathrm{mg} / \text { simvastatin } 20 \mathrm{mg} \text {; HR, } \\
\text { hazard ratio; SHR, subdistribution hazard ratio; Cl, confidence interval; CV, cardiovascular; PCl, } \\
\text { percutaneous coronary intervention; CABG, coronary artery bypass grafting }\end{array}$} \\
\hline
\end{tabular}

\section{Figures}




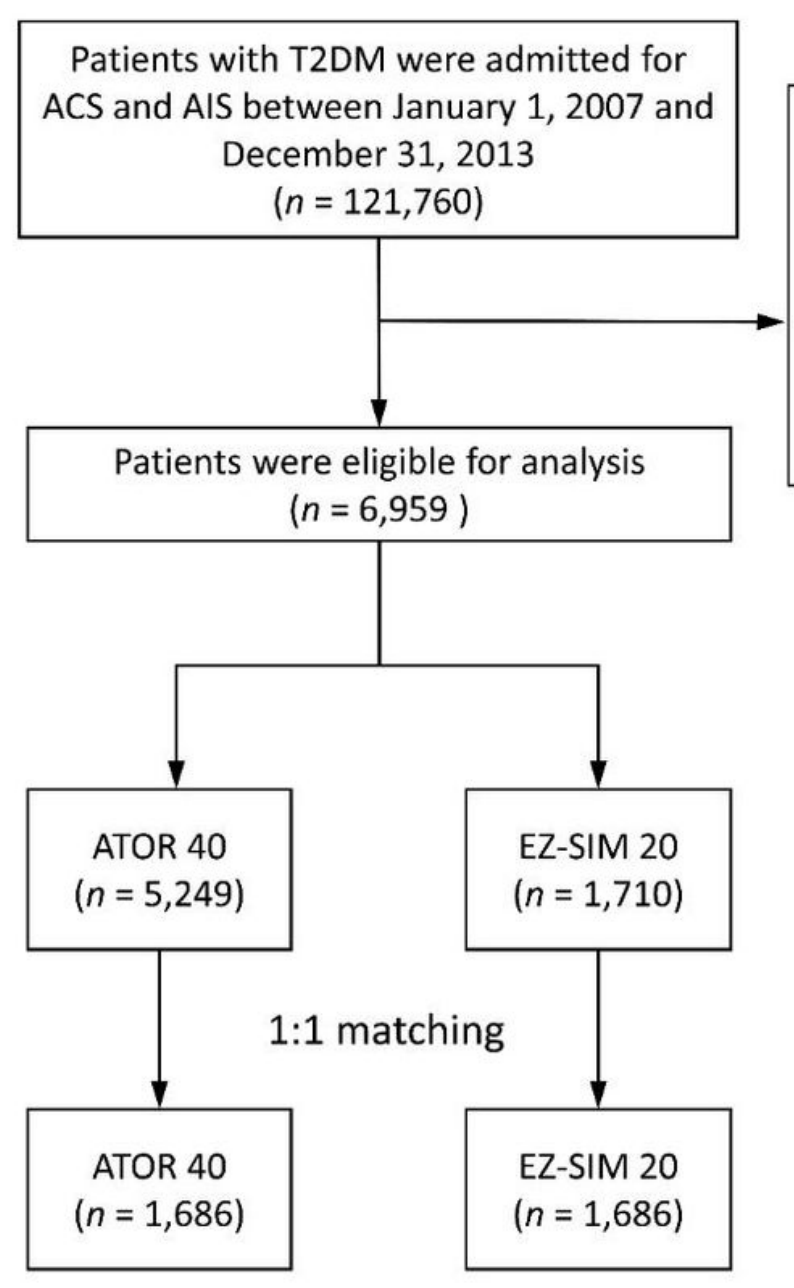

Patients were excluded:

Age $<40$ years: 764

Expired during index hospitalization: 5,882

Developed primary outcome within 30 days: 4,995

Follow-up less than 30 days: 1,843

Not prescribed any statins within 30 days: 70,927

Prescribed other statins within 30 days: 30,367

Prescribed two kinds of study drug at the time window: 23

\section{Figure 1}

Flow chart of selections of the study cohort 
A. Primary composite outcome

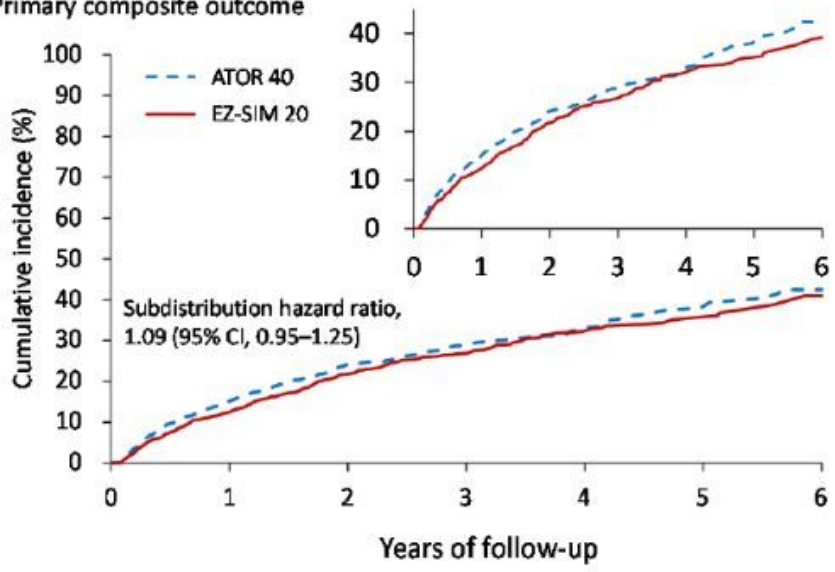

Number of patient at risk:

$\begin{array}{llllllll}\text { EZ-SIM 20 } & 1686 & 1172 & 793 & 481 & 240 & 90 & 18 \\ \text { ATOR 40 } & 1586 & 1134 & 731 & 437 & 215 & 80 & 18\end{array}$

C. Non-fatal myocardial infarction

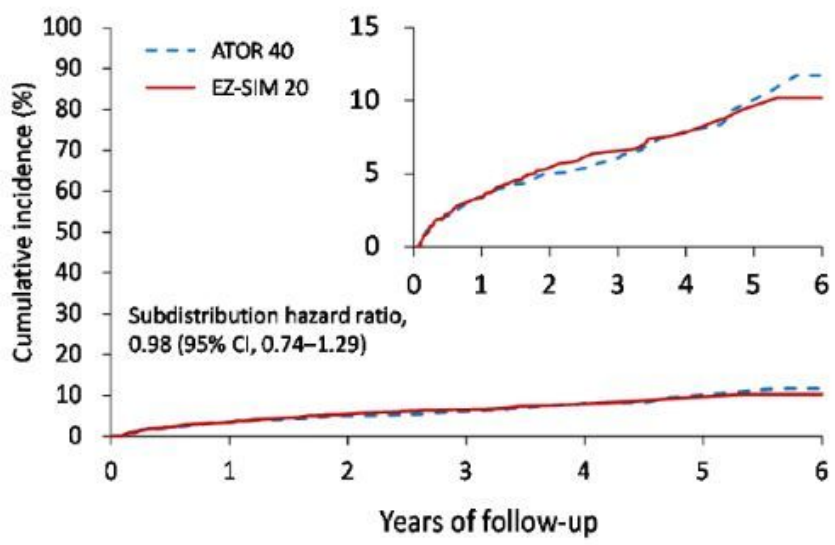

\begin{tabular}{llllllll}
\multicolumn{2}{l}{ Number of patient at risk: } & & & & & \\
EZ-SIM 20 & 1586 & 1250 & 893 & 559 & 287 & 107 & 25 \\
ATOR 40 & 1585 & 1284 & 896 & 568 & 279 & 110 & 29
\end{tabular}
B. Cardiovascular death

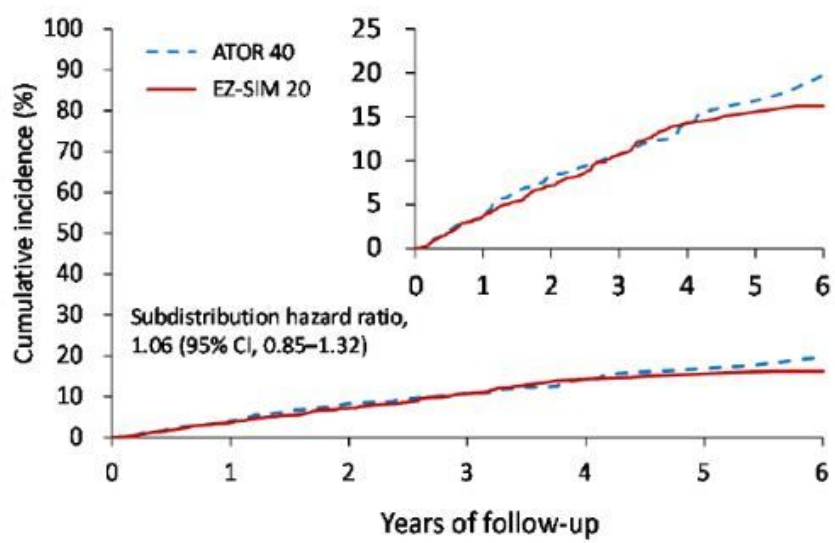

Number of patient at risk:

$\begin{array}{llllllll}\text { EZ-SIM 20 } & 1686 & 1284 & 931 & 583 & 308 & 115 & 29 \\ \text { ATOR 40 } & 1685 & 1284 & 896 & 568 & 279 & 110 & 29\end{array}$

D. Non-fatal stroke

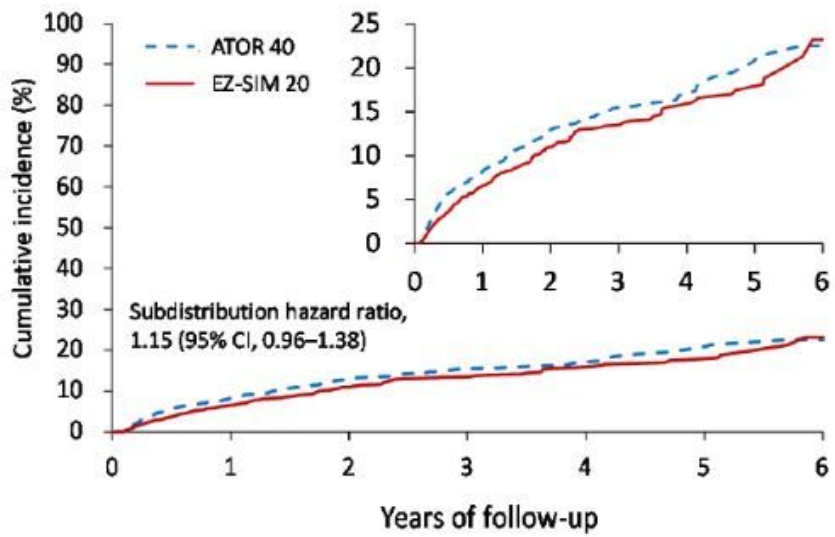

Number of patient at risk:

$\begin{array}{llllllll}\text { EZ-SIM } 20 & 1686 & 1203 & 829 & 504 & 259 & 97 & 20\end{array}$

\section{Figure 2}

The cumulative incidence of the primary composite outcome $(A)$, and the individual outcomes of cardiovascular death (B), non-fatal myocardial infarction (C) and non-fatal stroke (D) in the propensity score matched cohorts 
A. Secondary composite outcome

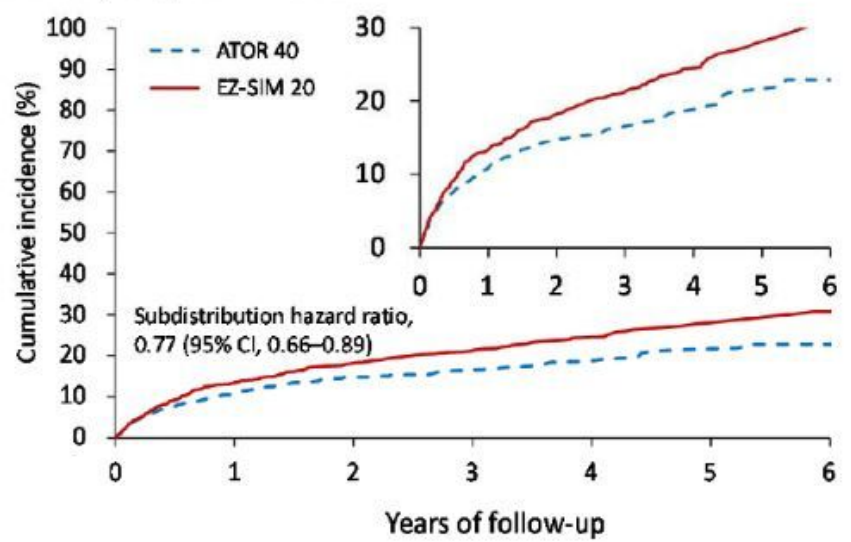

Number of patient at risk: $\begin{array}{llllllll}\text { EZ-SIM 20 } & 1686 & 1118 & 774 & 464 & 233 & 82 & 16 \\ \text { ATOR 40 } & 1686 & 1147 & 754 & 472 & 225 & 83 & 19\end{array}$

C. Percutaneous coronary intervention

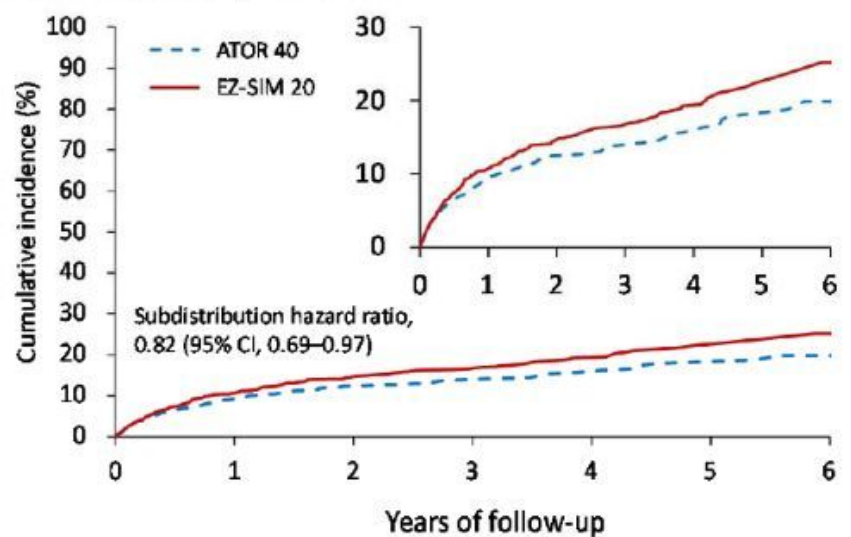

Number of patient at risk:

$\begin{array}{llllllll}\text { EZ-SIM 20 } & 1685 & 1154 & 808 & 492 & 245 & 88 & 18 \\ \text { ATOR 40 } & 1685 & 1165 & 784 & 486 & 233 & 88 & 20\end{array}$

B. Hospitalization for unstable angina
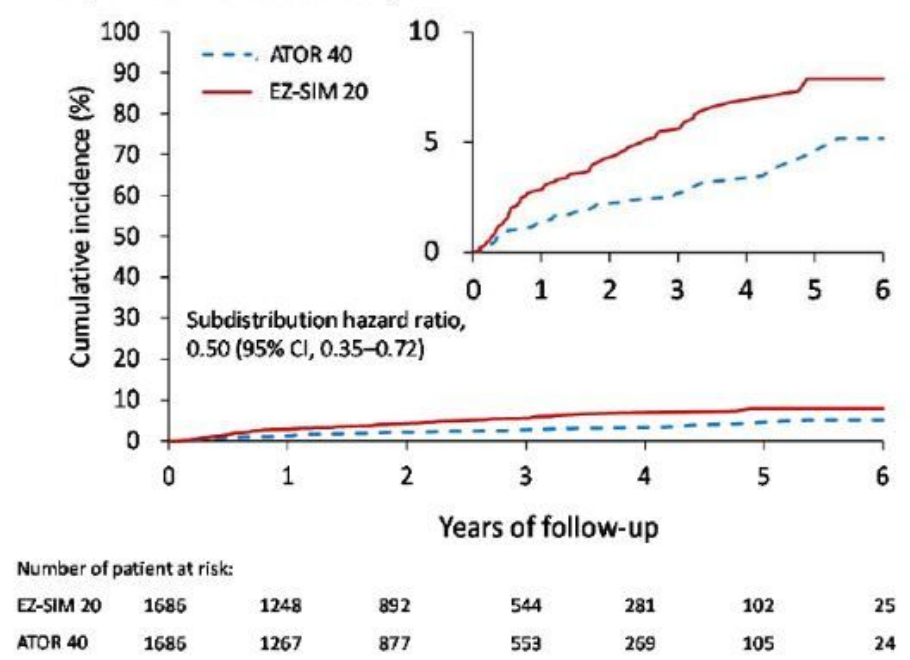

D. Coronary artery bypass graft
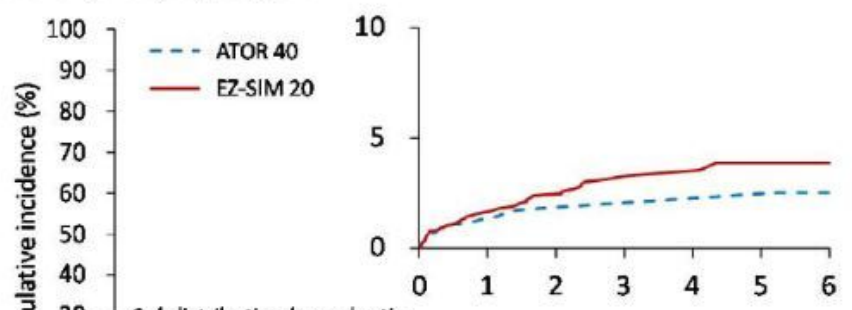

Subdistribution hazard ratio,

$0.62(95 \% \mathrm{Cl}, 0.40-0.97)$

10

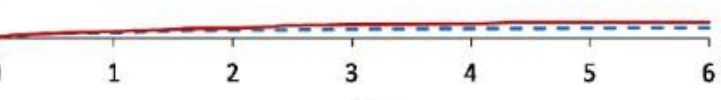

Years of follow-up

Number of patient at risk:

$\begin{array}{llllllll}\text { EZ-SIM } 20 & 1585 & 1266 & 914 & 569 & 303 & 110 & 27\end{array}$

$\begin{array}{llllllll}\text { ATOR } 40 & 1585 & 1268 & 878 & 556 & 272 & 106 & 28\end{array}$

\section{Figure 3}

The cumulative incidence of the secondary composite outcome (A), and the individual outcomes of hospitalization for unstable angina (B), percutaneous coronary intervention (C) and coronary artery bypass grafting $(D)$ in the propensity score matched cohorts 


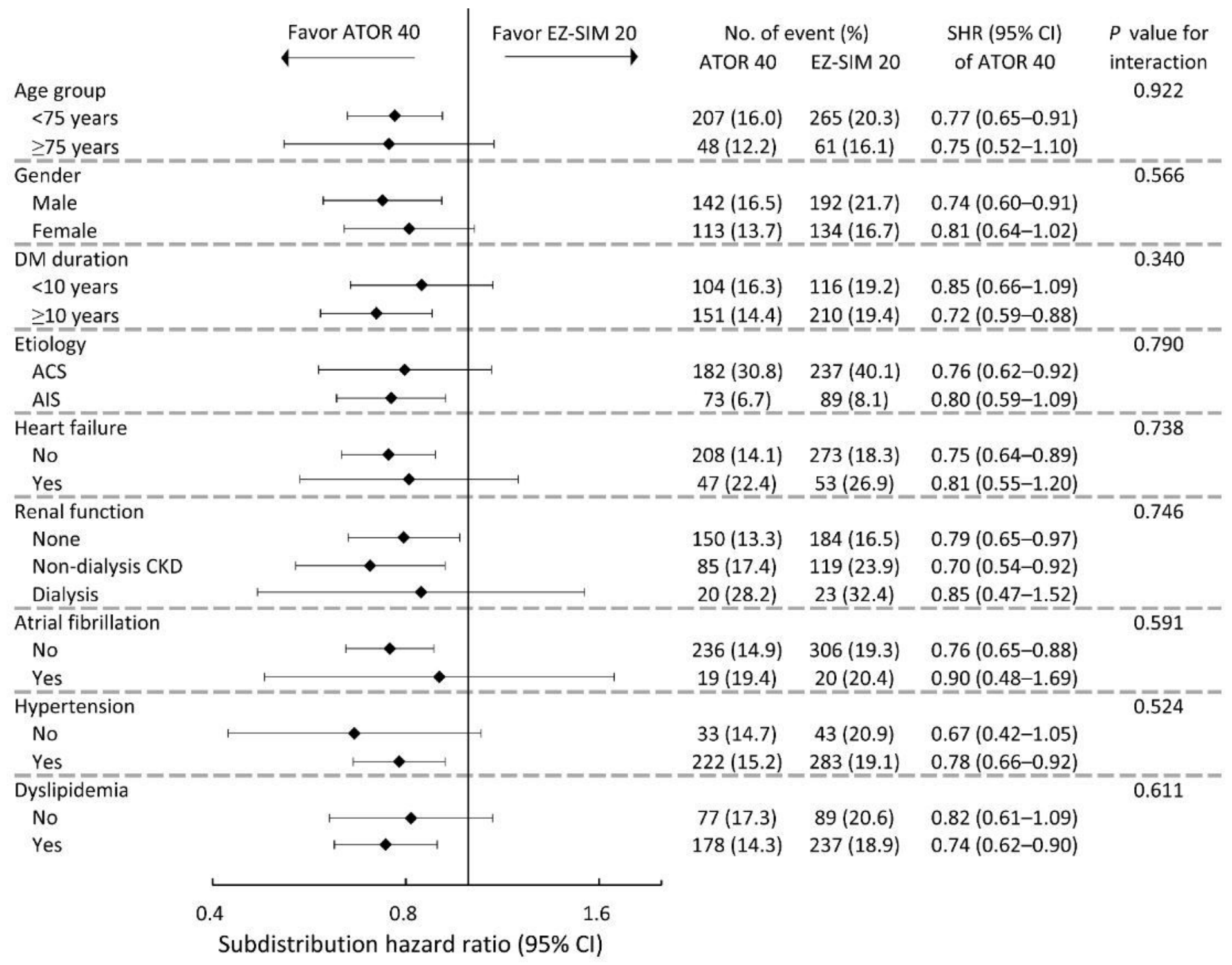

Figure 4

The post-hoc subgroup analysis of the secondary composite outcome

\section{Supplementary Files}

This is a list of supplementary files associated with this preprint. Click to download.

- Legendforsupplementaltable.docx

- SupplementalTable1.docx 